\title{
A PESCA ARTESANAL E A COMUNIDADE DO JARAGUÁ: UM MAPEAMENTO CIENTÍFICO
}

Rony Jefferson Albuquerque Farias ${ }^{1}$

Valter Silva ${ }^{2}$

Ronaldo Gomes Alvim ${ }^{3}$

Resumo: A pesca artesanal é uma das atividades de subsistência mais antigas realizadas pelo ser humano e apresenta importância cultural e econômica no município de Maceió/AL. A comunidade de pescadores do Jaraguá é uma das mais antigas e de grande importância história porém há necessidade de refletir sobre sua relevância científica. Por esta razão a presente pesquisa tem por objetivo mapear a literatura utilizadando Google acadêmico e a biblioteca virtual da SCieLO referente a esta comunidade. Inicialmente, foram utilizados os seguintes descritores: "multiculturalismo", "pluralismo jurídico", "pesca artesanal", "Jaraguá" e "meio ambiente". Mas em virtude dos resultados obtidos esses descritores foram reduzidos para "multiculturalismo", "pesca artesanal". O que foi possível perceber é a carência de pesquisas referentes a comunidade de pescadores do Jaraguá, sendo todas elas referentes ao período da remoção compulsória das famílias dos pescadores para os diversos conjuntos residenciais. Concluiu-se, então, que são necessários estudos focados numa visão interdisciplinar e holísta da referida comunidade diante de complexidade das relações sociais envolvidas no tema.

Palavras-chave: Pesca Artesanal, Jaraguá, Revisão Literatura.

\footnotetext{
${ }^{1}$ Mestre em Sociedade, Tecnologias e Políticas Públicas. Advogado e Servidor Público. E-mail:ronyfariasadv@gmail.com

2 Doutor em Ciênicas na área de concentração de Saúde Baseada em Evidênicas pelo programa de pós graduação em Medicina Interna e Terapêutica da UNIFESP. E-mail: v.silva@ymail.com

3 Doutor em Meio Ambiente Natural e Humano em Ciências Sociais pela Universidade de Salamanca,

USAL, Espanha (2005). E-mail: ecohumano@yahoo.com
} 
Abstract: Artisanal fishing is one of the oldest subsistence activities carried out by the human being and presents cultural and economic importance in the municipality of Maceió / AL. The fishing community of Jaraguá is one of the oldest and of great importance history but there is a need to reflect on its scientific relevance. For this reason the present research aims to map the literature using Google academic and the virtual library of SCieLO referring to this community. Initially, the following descriptors were used: "multiculturalism", "legal pluralism", "artisanal fishing", "Jaraguá" and "environment". But in virtue results obtained these descriptors were reduced to "multiculturalism", "artisanal fishing". What was possible to notice is the lack of research concerning the community of fishermen of Jaraguá, all of them referring to the period of compulsory removal of the families of the fishermen to the different residential groups. It was concluded, therefore, that studies are needed focused on an interdisciplinary and holistic view of the said community in view of the complexity of the social relations involved in the theme.

Keywords: Artisanal Fishing, Jaraguá, Literature Review.

\section{Introdução}

A pesca artesanal de subsistência foi uma das primeiras atividades desenvolvidas pelo homem. Com a chegada dos colonizadores portugueses às terras brasileiras, estes encontraram povos nativos seminômades que desenvolviam atividades de caça, pesca e colheita natural (PRADO JÚNIOR, 2012).

Segundo a Organização das Nações para Agricultura e Alimentação (FAO) (2014) estima-se que a atividade pesqueira e a aquacultura são, hoje, o sustento de 10 a 12 por cento de toda a população mundial e, consequentemente, sendo responsável direta por aproximadamente 17 por cento do consumo de proteína no planeta, mas chegando a $70 \%$ em alguns países costeiros e insulares.

No caso do Brasil, segundo dados do Ministério da Agricultura, Pecuária e Abastecimento (BRASIL, 2013), em seus 8,5 mil quilômetros de costa marítima e 8,2 milhões de metros cúbicos de água em rios, lagos açudes e represas, este ocupa a $23^{\circ}$ posição no ranking mundial e 4ํㅜ posição entre os países da América Latina em produção de pescado no mundo. Embora possa parecer tal detalhe como destaque, na verdade, no país ainda é incipiente a produção aquícola se comparada a dos maiores produtores mundiais, como a China, a Índia, o Vietnã e a Indonésia (FAO, 2014).

Em 2009 a Lei n. 11.959 revogou o Código de Pesca de 1967 e entre outras disposições, em seu art. $8^{\circ}$, definiu pesca artesanal como:

[...] aquela praticada diretamente por pescador de forma autônoma ou em regime de economia familiar, com meios de produção próprios ou mediante contrato de parceria, desembarcado, podendo utilizar embarcações de pequeno 
porte, (...) determinando ainda como embarcação de pequeno porte aquela de até $20 \mathrm{AB}$ (toneladas de arqueação bruta). (BRASIL, 2009, art.8)

A Organização Internacional do Trabalho (OIT), no ano de 2007, criou a convenção 188. Em suas discussões, trouxe vários temas a serem debatidos dentre eles, importância da pesca extrativista. $O$ intuito era assegurar que os pescadores tenham condições decentes de trabalho a bordo de embarcações com relação a exigências mínimas para trabalho a bordo; condições de serviço; acomodação e alimentação; proteção à segurança e saúde ocupacionais; assistência médica e seguridade social e é nesse sentido que será mensurada a condição de meio ambiente de trabalho do pescador artesanal.

Esse ambiente da pesca e sua normatividade precisam conviver em harmonia. Para que isso ocorra a efetividade da norma jurídica é necessária. Assim, vamos a uma breve explicação quanto ao entendimento adotado. Apesar de algumas divergências entre os teóricos, a efetividade refere-se à eficácia de caráter social de uma norma jurídica, isto significa que esta norma (lei em sentido amplo) alcançou a sua função na sociedade, que no mundo real, a norma foi aceita, recepcionada, sendo este o entendimento que será adotado.

Segundo Barroso (2001, p. 85) diz que "a efetividade (...) simboliza a aproximação, tão íntima quanto possível, entre o dever ser normativo e o ser da realidade social".

É assim entender a efetividade de uma norma é essencial para a qualidade de vida e de trabalho de qualquer pessoa. Com a comunidade de pescadores do Jaraguá, objeto desta pesquisa, não seria diferente.

\section{A pesca artesanal e a comunidade do Jaraguá}

No Estado de Alagoas há muitas comunidades pesqueiras. Na cidade de Maceió, capital e município litorâneo com um grande potencial para a pesca, é notória essa expectativa, mormente, no bairro do Jaraguá. Alguns historiadores e antropólogos atribuem à origem da cidade à vila de pescadores deste tradicional bairro (ALBUQUERQUE, PEIXOTO; ALBUQUERQUE, 2012). A antiga Vila está localizada (Figura 1) entre o Porto de Maceió e a Associação Alagoana de Vela e Motor, na Avenida Industrial Cícero Toledo, em frente ao prédio histórico que hoje abriga a Associação Comercial de Alagoas e o Museu da Imagem e Som de Alagoas (MISA) e ao estacionamento por trás da Delegacia da Receita Federal em Alagoas. 


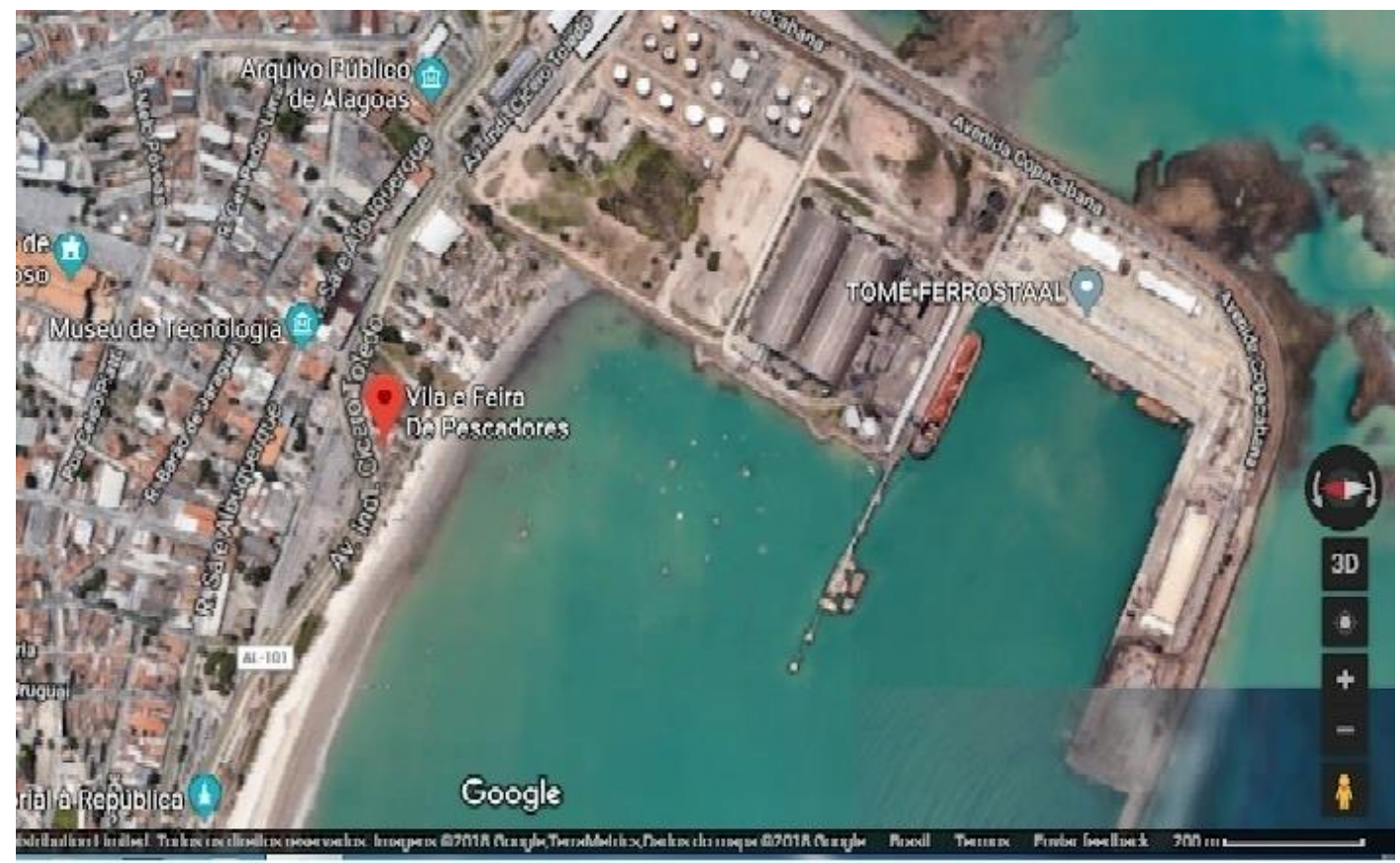

Figura 1: Vila dos pescadores de Jaraguá

Fonte: Google Maps, 2018

Atualmente os pescadores utilizam as edificações da Vila do Jaraguá como depósito e pontos de venda, no entanto num passado não tão distante, até a primeira década dos anos dois mil, a vila era o local de moradia desses pescadores e suas famílias. Até meados dos anos 80 a vila era composta de muitas famílias de pescadores tradicionais, porém sucessivas ações do Poder Público, na intenção dolosa de "favelizar" o local ao transferir desabrigados de enchentes para a vila de pescadores, contribuíram por agravar o problema da permanência da vila no local, somado a negligência da própria municipalidade quanto as mais diversas formas de assistências, como por exemplo o acesso a saúde pública, coleta de lixo, saneamento básico entre outras questões relacionadas a subtração de direitos sociais básicos (ALBUQUERQUE, PEIXOTO; ALBUQUERQUE, 2012).

Precisamente em 17 de junho de 2015, segundo Marchioni (2016) a vila de pescadores do Jaraguá foi totalmente desocupada, sendo 25 famílias removidas para um conjunto habitacional de nome: Residencial Vila dos Pescadores, distante $4 \mathrm{~km}$ e localizado no bairro do Trapiche da Barra. Outras 100 famílias restantes foram distribuídas em abrigos e outros conjuntos, passando a receber um auxílio moradia por prazo determinado, ficando claro o total desrespeito aos Direitos Humanos e as normas internacionais que protegem o "direito à moradia adequada". 
Invariavelmente, são as comunidades em condição de maior vulnerabilidade social e econômica aquelas que mais sofrem com os deslocamentos forçados, legitimados pela estigmatização e pelo preconceito, a partir da classificação de hierarquia social, refletidas nos assentamentos precários. (MARCHIONI, 2016)

Sendo assim, sob o pretexto de conter a "favelização" da vila produzida em parte pelo próprio poder público; a necessidade de se urbanizar a orla, fundamentado no plano diretor da capital, e ainda com a promessa da construção de um mercado de peixe com excelente estrutura como contrapartida aos pescadores, ainda não concluído até a presente data, a municipalidade removeu com uso da força e legitimado pelo Ministério Público Federal todos os pescadores, transferindo-os para aluguéis sociais e/ou apartamentos no condomínio residencial no Trapiche da Barra. Tal posicionamento não levou em consideração as condições de comunidade tradicional, e a importância de se preservar a memória cultural do município e, nem tão pouco a importância da pesca artesanal para nosso Estado e para a sobrevivência dos pescadores.

A comunidade do Jaraguá tentou ser reconhecida como comunidade tradicional para ter garantida sua permanência, porém não teve êxito. No entanto, para Marchioni a comunidade pesqueira do Jaraguá era tradicional no sentindo de que:

De acordo com o Instituto de Patrimônio Histórico e Artístico Nacional - IPHAN, a comunidade possui características que demonstram a sua tradicionalidade, a exemplo do seu vocabulário peculiar: "mestrar" (comandante do barco), "garateia" ou "fateja" (âncora), "rancho" (fogão nos barcos), "quarenta" (comida à base de fubá que alimenta uma família pequena) (MARCHIONI, 2016, p 30)

Entendemos que uma comunidade de pescadores artesanais pode ser considerada um grupo étnico com uma cultura peculiar, a exemplos dos povos indígenas, comunidades quilombolas, povos ciganos entre outros, visto que o diálogo entre as gerações sobre os fatores naturais que influenciam no desenvolvimento da pesca constitui uma importante estratégia para a preservação/conservação dos conhecimentos tradicionais, assim como para a manutenção da própria atividade (MARTINS e ALVIM, 2016) e que, portanto merece um olhar e tratamento diferenciado.

Os pescadores e pescadoras artesanais possuem tradicional modo de viver e de lidar com a natureza; têm história e cultura 
de raízes profundas, que são passadas de geração para geração. A pesca é mais que uma profissão, é um modo de vida no qual o trabalho é livre e tem um regime autônomo e coletivo, extraindo da natureza somente o que ela é capaz de repor. Possuem, portanto, relação de transformação direta da natureza, com espiritualidade e mística, que suscitam respeito e cuidado. (TÓMAZ; MARQUES, 2014, p. 410)

A prática da pesca artesanal "se baseia em relações de parentesco, amizade e vizinhança enriquecendo as tramas sociais e afetivas em relação ao lugar de moradia e seu trabalho" (MARTINS; ALVIM, 2016, p. 388). A jurisdição, ou seja, a quem competer aplicar o direito, tem sua importância para a sustentabilidade dos aspectos socioambientais na medida em que confere segurança jurídica à comunidade em conflitos ambientais complexos (TREVIZAN. LEÃO, 2014 p.551). Além disso, há necessidades socioeconômicas dos seres humanos com a preservação do meio ambiente, havendo também um direcionamento para a sustentabilidade de futuras gerações (OLIVEIRA, 2012).

Entretanto, devido sucessivos acontecimentos históricos como, por exemplo, a expulsão das famílias dos pescadores da antiga "Vila do Jaraguá" por parte da municipalidade, direcionando-os para pontos diversos da cidade, muitos deles para bairros distantes do mar, e a própria necessidade de se buscar outros meios de sustento fizeram com que esta comunidade perdesse ao longo do tempo muito de suas características tradicionais.

Os estudos sobre a comunidade de pescadores artesanais da vila do Jaraguá se referem, em sua maioria, a época em que a municipalidade estava promovendo a remoção dos moradores para condomínios residenciais, com a intenção de promover uma regularização fundiária urbano-ambiental.

Torna-se necessário compreender como essa comunidade continua exercendo sua atividade de pesca artesanal e de que forma vem se reproduzindo; seu modo de se relacionar com a natureza e desenvolver técnicas que garantam a subsistência de suas famílias, como cuidar do seu meio ambiente de trabalho, se prevenindo ou minimizando os acidentes de trabalho e as doenças ocupacionais e como qual o papel do SDPA diante de todo esse quadro. Portanto, a relação dessas condutas e percepção do destinatário do benefício com a norma jurídica (lei no sentido amplo).

Logo a comunidade do Jaraguá continua desenvolvendo sua cultura, no sentindo mais simplificado da palavra, como um conjunto de processos com intuito de sobrevivência e civilização do grupo. 


\section{Resultados e discussões}

\section{Referencial teórico}

O marco teórico apresentado é a Teoria Crítica do Direito, que busca nas lutas e resistência ao sistema econômico global sua própria constituição e assim materializar os bens necessários a uma vida digna (OLIVEIRA NETO; REBOUÇAS, 2016).

Os Direitos Humanos nos trazem uma proposta de criação de um núcleo comum de direito, isto através da força cogente da supremacia desses direitos, dessa forma esses Direitos Humanos devem ser entendidos como um direito hierarquicamente acima que os direitos dos países do mundo, atribuindo-se assim um caráter universal.

Com o desafio de afastar os problemas da universalidade e o relativismo trazido pelo multiculturalismo (aceitação e respeito às diferentes culturas) e, diante dessa dicotomia que acredita ser uma das barreiras a sua efetividade, proteger a pessoa humana e todas as formas de sua dignidade (GALVÃO, 2016).

No Brasil o pluralismo jurídico é defendido por Antônio Carlos Wolkmer através de um "pluralismo jurídico comunitário-participativo" onde se propõe uma mudança de paradigma da cultura jurídica com base numa ideia de participação, eficácia social e consenso comunitário (WOLKMER, 2001).

Deste pensamento multicultural decorrem outras teorias tais como o pluralismo jurídico e deste o termo "Etnodireito" como um novo conceito a ser construído. Advindo da Ciência da ecologia humana, visa observar os povos e comunidades tradicionais através de uma visão crítica e multicultural do Direito, reconhecendo que povos tradicionais, através de seus costumes, criam obrigações, regras de conduta e leis próprias (TÓMAZ; MARQUES, 2014).

Sendo assim, a atividade laboral deve ser observada não apenas pela ótica do Direito estatal, mas também pela visão dos sujeitos que integram esse ambiente. Neste caso, o Direito ambiental e do trabalho dialogam diretamente quanto ao tema do ambiente de trabalho uma vez que o conceito abrange não só o entorno físico-natural quanto o artificial.

José Afonso da Silva aplica seu entendimento ao meio ambiente como algo amplo, ultrapassando a esfera biológica para incluir o artificialismo, isto é, criado pelo próprio homem, abrangendo os bens culturais correlatos compreendendo, portanto, o solo, a água, o ar, a flora, as belezas naturais, o patrimônio histórico, artístico, turístico, paisagístico e arqueológico (SILVA, 2004).

Desta forma, o ambiente de trabalho é o local onde o profissional autônomo que desempenha suas funções laborais sem um horário fixo, isto é, sem reconhecimento de vínculo empregatício, neste caso o pescador artesanal, o sujeito do estudo.

Entende-se como pescador artesanal aquele que confecciona e repara seus petrechos de pesca e reparo nas embarcações de pequeno porte, onde 
armazena, processa e comercializa o produto, e naturalmente o ambiente da embarcação, onde captura o pescado (DIEGUES, 1983).

Para o pescador artesanal, o meio ambiente de trabalho se confunde com o meio ambiente natural fato que aproxima ainda mais esses saberes criando para alguns autores um novo ramo do conhecimento chamado de Direito Ambiental do Trabalho (CARVALHO et. al, 2014).

Na verdade, o campo do Direito do trabalho é um terreno fértil para a compreensão da vida dos pescadores artesanais sobre a visão do pluralismo jurídico. Verifica-se nas comunidades e agrupamentos sociais, a sobreposição de normas de origem estatal e não estatal, a exemplo das normas coletivas do trabalho, acordos e convenções, que advém dos sindicatos e dos próprios grupos que regulam e determinam a forma, a exploração e condutas para a atividade pesqueira. Ainda que de forma temporária e hierarquizada (SANTOS, 2009). Nas palavras do autor esse pluralismo jurídico recebe uma nomenclatura específica também expressada como "autonomia privada coletiva".

No entanto, de nada adianta criar normas jurídicas para proteger o meio ambiente de trabalho dos pescadores artesanais se não for levada em consideração as peculiaridades da comunidade. Neste instante, o Direito aplicado à Ecologia Humana demonstra aplicabilidade nos estudos às diversas áreas do conhecimento, abrindo espaços a novos conceitos e valores que se intersectam (ALVIM, 2012 p. 22) regidas, principalmente, por forte teor político e social. (BATES; LEES, 1996; BATES, 2005).

É essencial conhecer sua cultura, seu modo de vida e especialmente, seu modo de trabalho para que a norma jurídica se aproxime o máximo possível de sua função social, alcance efetividade.

Assim é entendido o multiculturalismo: um "cruzamento interdisciplinar entre normatividade (Direito) e Poder Social (Sociedade)". Numa perspectiva interdisciplinar entre o Direito e outros campos do conhecimento é totalmente possível uma "juridicidade policêntrica", ou seja, um direito oriundo da convergência de várias fontes, onde se alcance as necessidades reais de uma comunidade. (WOLKMER, 2001).

Um Direito formado por vários "direitos" como, por exemplo: direito de uma comunidade religiosa, direito de uma comunidade étnica, direito de um núcleo familiar, direito de uma categoria profissional entre outros direitos sociais, sendo esses "direitos" informais estudados por uma pesquisa social de vertente empírica.

Faz-se necessário uma abordagem interdisciplinar uma vez que a norma jurídica por si só não tem o poder de mudar a realidade das pessoas diante da complexidade inerente ao ser humano.

Por meio do Direito interconectado a outras disciplinas busca-se compreender a vida do pescador artesanal. Para isso o diálogo com diversas áreas do conhecimento como as Ciências Sociais, a Antropologia, a Biologia e 
as Ciências Ambientais foram de fundamental importância para a realização do presente trabalho.

Realizamos uma revisão de literatura sobre meio ambiente da pesca artesanal, partindo de pesquisadores de áreas diversas, no qual de forma interdisciplinar, buscou-se entender a relação do pescador artesanal e o meio ambiente.

\section{Revisão de literatura}

Em uma comunidade tradicional de pescadores artesanais a atividade de pescar é encarada como forma de sobrevivência, pois, os pescadores, em sua grande maioria, apresentam baixa escolaridade e, portanto, muita dificuldade em se inserir no mercado de trabalho formal (DIEGUES, 1983).

Este mesmo autor (DIEGUES, 1983) define pescadores artesanais como aqueles que, na captura e desembarque de toda classe de espécies aquáticas, trabalham sozinhos e/ou utilizam mão-de-obra familiar ou não assalariada, explorando ambientes ecológicos localizados próximos à costa, pois em geral a embarcação e aparelhagem utilizadas para tal fim possuem pouca autonomia, sendo mais exigida a experiência e manejo do pescador para o desempenho da atividade da pesca.

Entende-se que a pesca artesanal pode ocorrer no meio urbano como no meio rural, isto porque nos dois espaços se apresentam diferentes perspectivas no que diz respeito a serviço de habitação e infraestrutura. Logo, o meio ambiente da pesca possui características bem peculiares.

Enquanto que o estilo de vida do pescador artesanal do ambiente rural está normalmente interligado à produção agrícola e à utilização de artefatos na maioria dos casos arcaicos, sem utilização de equipamentos de proteção; o pescador artesanal urbano se encontra vinculado, em muitos casos, a precariedade de moradias e de infraestrutura, com deficiência de sistema de abastecimento de água, esgotamento sanitário e coleta regular de lixo. Porém, o conhecimento popular da pesca do pescador rural e urbano são muito semelhantes. Abrange inúmeros aspectos, tais como: hábitos de migração, alimentação, época e lugares de desova dos cardumes, desenvolvimento de técnicas de captura como armadilhas fixas de baixo impacto sobre a fauna (RESENDE, 2006).

Conhecimentos estes, empíricos, mas que são insuficientes para lidar com determinados problemas e muitas vezes põem em riscos sua saúde e segurança, além de ser danoso ao ambiente. Apesar de que, segundo levantamentos realizados pelo Ministério da Pesca e Aquicultura (BRASIL, 2011) o principal problema enfrentado pelas famílias que sobrevivem da pesca artesanal no Brasil é a degradação ambiental ocasionada pelos grandes empreendimentos industriais e portuários. 
No contexto de Maceió, sendo, notadamente, as obras da nova dragagem do porto da cidade uma grande preocupação para a comunidade do Jaraguá atualmente.

Existe uma clara precariedade nas práticas artesanais em razão da falta ou deficiente instrução social e inserção nos contextos de tomada de decisões. No âmbito da educação, tanto no ambiente rural quanto urbano, percebe-se uma ausência da educação de base que contribua para a conscientização para boas práticas ambientais. As comunidades de pescadores que exercem atividades em estreita relação de uso e dependência de recursos naturais incorporam conhecimentos de processos que são conhecidos como conhecimento ecológico local (LIMA; DORIA; FREITAS, 2012).

A pesca artesanal é uma atividade extrativista que se assemelha em parte a pesca predatória, pois não existe controle para se manter o equilíbrio ecológico da vida marinha, somente uma extração desenfreada. Porém, até mesmo por uma questão conceitual, na pesca artesanal todos os apetrechos e ferramentas utilizados são de baixa ou nenhuma tecnologia e produzidas pelos próprios pescadores.

Se a atividade da pesca extrativista obedecesse às condições de reprodução da fauna aquática, o ecossistema se manteria em equilíbrio, retirando apenas o excesso de espécies, sem prejudicar a fertilidade e o processo de reprodução animal e vegetal marinha. Mas, o que se verifica é uma pesca industrial (não artesanal) predatória realizada em alto mar e com objetivo de capturar grandes peixes e até tubarões, fazendo até uso de ferramentas sofisticadas de captura (DI CIOMMO, 2007).

$\mathrm{Na}$ estrutura de comércio do resultado da pesca, é comum que tanto as moradias dos pescadores quanto o setor de comércio do produto pescado sejam próximos ao local de pesca. As balanças do comércio de pescado devem ser dotadas de práticas e materiais de limpeza e higiene, observando as exigências da vigilância sanitária. Torna-se necessário a mobilização das colônias de pescadores e associações, juntamente com a gestão de cada município, para que se atue de modo a se investir no ambiente de comércio do pescado, na instrução dos setores de fiscalização e no investimento financeiro para a manutenção do local (FREITAS; RODRIGUES, 2015).

Ponderando-se sobre o meio ambiente da pesca numa comunidade tradicional e artesanal percebe-se a necessidade da intervenção estatal uma vez que, quanto o local da pesca propriamente dito, a pesca artesanal pode ser realizada em ambiente marinho e/ou lagunar/estuarino e ambos, notoriamente, sofrem com as ligações clandestinas de redes domésticas e industriais de esgoto (VERAS, 2015)

Diante desta problemática é necessário que o poder público através dos órgãos ambientais desempenhe uma efetiva e constante ação de fiscalização e conscientização dessas comunidades quanto às redes de canalização de água pluvial e de esgoto sanitário, para que tenham a destinação correta. Uma vez que se destinam resíduos ou esgoto em tubulações pluviais, estes desaguarão 
no curso das bacias hidrográficas, gerando custos maiores para o controle da quantidade e qualidade da água, que quando não ocorre, prejudica a vida marinha e de quem vive nas proximidades.

Como o ambiente de pesca é visto simultaneamente pelos pescadores como seu campo de atuação profissional e um ambiente doméstico, pois assim que é usufruído por estes profissionais e suas respectivas famílias. Se faz necessário a consciência, não somente por profissionais da área ambiental, mas pelos principais envolvidos, de que o cenário em questão trata-se de um ambiente aquático com uma biodiversidade presente. (FARIAS, et al., 2017)

Assim o meio ambiente da pesca artesanal apresenta características peculiares que devem ser encaradas de forma multifatorial e sob uma perspectiva interdisciplinar, sendo necessárias políticas que implementem a educação ambiental como forma de tornar a atividade extrativista da pesca artesanal mais sustentável, reconhecendo a complexidade do tema ambiental e a obrigatoriedade de enxergar o tema com as lentes da interdisciplinaridade.

Porém, o retorno com tal abordagem não respondeu de modo satisfatório a problemática da presente pesquisa e optamos por um estudo mais profundo e sistematizado em base de dados virtuais e com métodos previamente definidos. Assim, efetivamos um mapeamento da produção científica.

\section{Mapeamento da produção científica}

Mapeando-se as pesquisas na Biblioteca Virtual Scientific Eletronic Library Online - SciELO, a partir de 2007, com os descritores: multiculturalismo $O R$ pluralidade $O R$ pluralismo jurídico $A N D$ pesca, percebe-se que não existem estudos específicos à comunidade de pescadores.

Ao utilizar apenas o descritor "multiculturalismo" constata-se que os estudos se limitam na grande maioria dos casos às comunidades indígenas, mas que vem apresentando produção científica crescente de ao longo do tempo, os anos de 2015 e 2016 os mais significativos em número de publicação (Grafico 1) e grande parte das pesquisas foram desenvolvidas por autores latinos americanos na língua espanhola (Gráfico 2). 


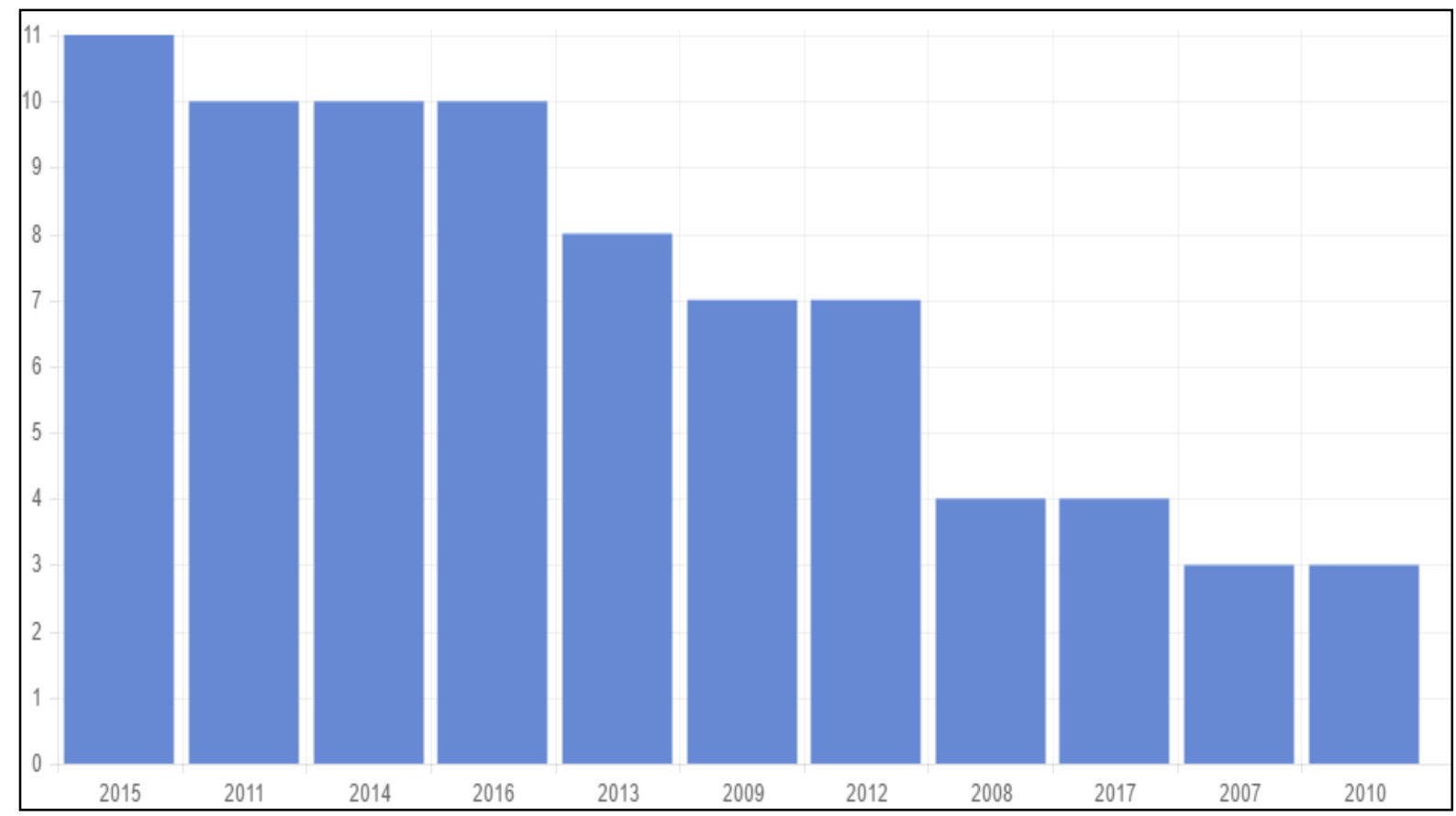

Gráfico 1: Número de artigos publicados por ano

Fonte: SciELO (2017a)

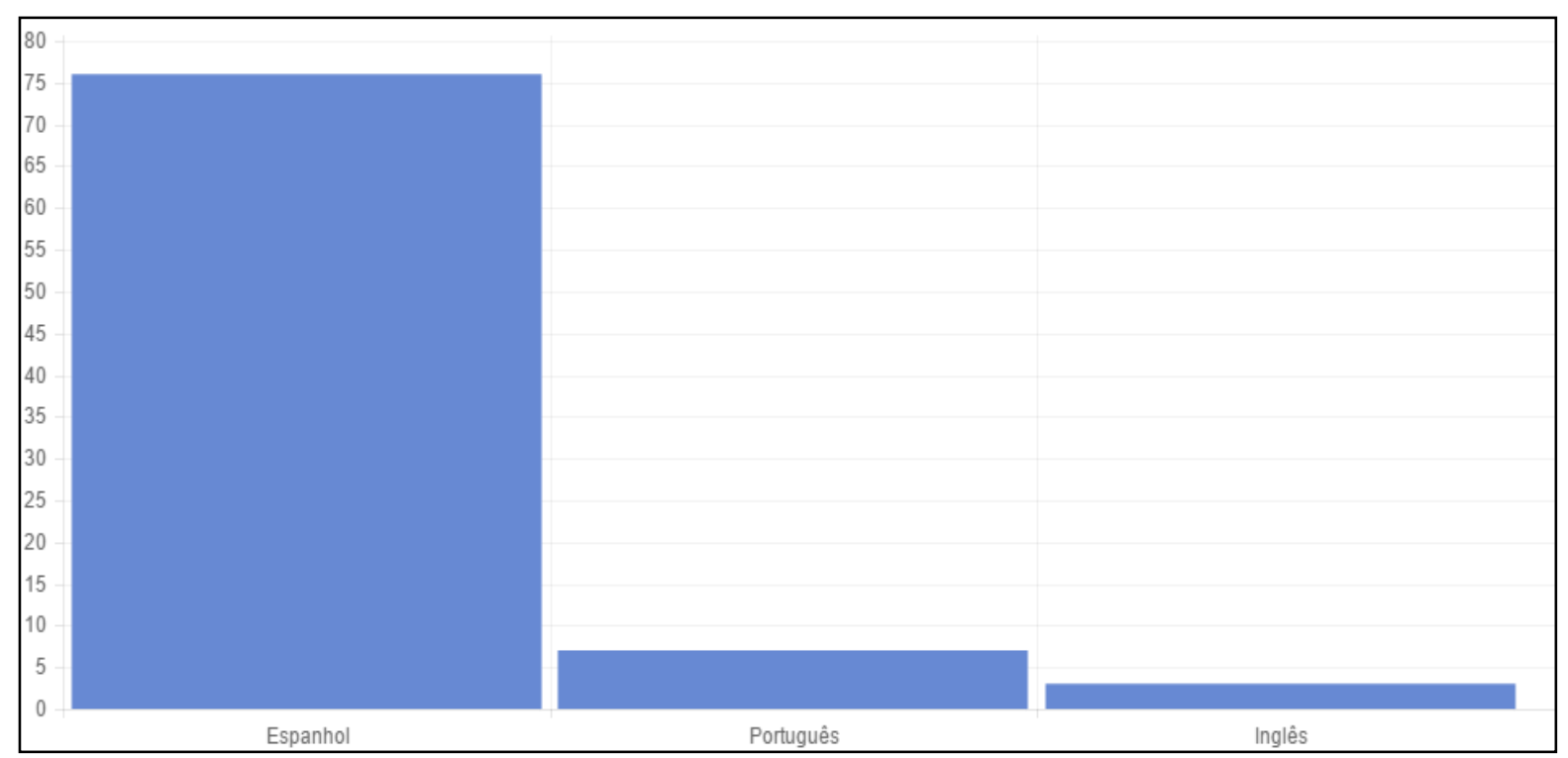

Gráfico 2: Número de artigos publicados por idiomas

Fonte: SciELO (2017b)

Através de um mapeamento da literatura sobre o tema, realizada na SciELO, utilizando os descritores: pesca artesanal, Direito Ambiental do Trabalho, Direitos Humanos, multiculturalismo, políticas públicas e acidente de trabalho, na última década, chegou-se aos seguintes resultados a seguir. 
Percebe-se que ao utilizar o descritor "pesca artesanal" isoladamente a maioria das pesquisas encontradas é do Brasil, embora isso possa ter ocorrido pelo uso do termo em português; 89 artigos estavam em revistas das Ciências Biológicas, Exatas e da Terra. Encontramos um total de 239 artigos. Quando se adiciona a buscar o descritor: trabalho, o total de artigos encontrados são reduzidos a 55 (cinquenta e cinco). Os critérios de inclusão dos artigos foram pertinência e aproximação com o tema e objeto desta pesquisa. Os artigos que apresentavam uma abordagem disciplinar ou exclusivamente quantitativa foram excluídos, uma vez que, a presente pesquisa tem como objetivo específico trabalho interdisciplinares e de cunho qualitativo ou misto. Assim, chegou-se a um total de 20 artigos para a discussão, apresentando a maioria desses trabalhos uma metodologia de cunho etnográfico ou de estudo de caso.

Utilizando-se o descritor pluralismo jurídico ou pluralidade jurídica ou multiculturalismo jurídico nota-se que num total de 85 trabalhos e em língua espanhola 76 artigos e, grande maioria deles aborda a população indígena defendendo sua autodeterminação jurídica (ROA, 2014; VARGAS; LASCARRO, 2015; ANDRADE, 2014; PINTO; AVILA, 2011). Dessa forma, entende-se que também se aplica tal abordagem aos pescadores artesanais devido a sua característica de comunidade tradicional.

No mesmo sentido se reconhece a existência dessa ordem jurídica não estatal, que apesar de não escrita sobrevive na memória das pessoas, a exemplo das mulheres extrativistas de mangaba no estado de Sergipe (MOTA; SCHMITIZ; SILVA JÚNIOR, 2015).

Nota-se que muitos autores se dedicam a estudar os riscos ocupacionais a que se submete o pescador artesanal. Riscos de doenças profissionais e acidentes de trabalhos, todos aliados a uma condição de vulnerabilidade social, derivam de uma sobrecarga extenuante de trabalho, lesões por esforço repetitivo (PENA; FREITAS; CARDIM, 2011; ALVIM, 2012) bem como acidentes típicos da atividade da pesca, que resulta em perfurações e cortes advindo muitas vezes de ataques de animais marinhos (FREITAS; RODRIGUES, 2015).

No entanto, como os pescadores artesanais são na grande maioria dos casos, trabalhadores autônomos e não tem registro na Carteira de Trabalho e Previdência Social (CTPS) não existem dados muito precisos, mas verifica-se que, ao estudar os pescadores no Tocantins, a incidência de acidente de trabalho, é classificada como "altíssima". A incidência de novos casos de acidentes laborais é de $85,9 \%$, ou seja, muito superior a média entre trabalhadores urbanos que é de apenas $5 \%$ ao ano (GARRONE NETO; CORDEIRO; HADDAD JR., 2005).

Como se não bastasse esse cenário hostil e danoso ao pescador artesanal, estudos demonstram a existência de um desgaste psicológico e social associado à atividade da pesca (FREITAS; RODRIGUES, 2015). Um estudo qualitativo de cunho narrativo pode ajudar a compreender quais as técnicas e procedimentos adotados no cotidiano do pescador, levando em consideração 
também que cada comunidade tem características próprias e "dinâmicas ecossociais singulares e/ou universais" (RAMALHO, 2016, p. 398).

As técnicas dentro de uma comunidade de pesca artesanal são ensinadas de pai para filho dentro de uma cadeia de produção familiar (DIEGUES, 1983), portanto nem sempre está escrita em nenhum documento ou foi positivada pelo Direito estatal como norma de proteção do ambiente de trabalho deste pescador.

Diante de toda a condição peculiar da pesca artesanal e sua vasta importância para a sociedade algumas políticas públicas, a exemplo do Programa Bolsa Família, já são consideradas altamente virtuosas (MOTA et al., 2014). Mas outras pesquisas demonstram que urge a criação de políticas públicas mais específicas destinadas a proteção do trabalho da pesca artesanal (MESQUITA; ISAAC-NAHUM, 2015).

Apesar da relevância em virtude dos interesses econômicos, a pesca artesanal é considerada como uma atividade que envolve um alto risco decorrente da precariedade das condições de trabalho, do elevado grau de insalubridade refletindo em doenças ocupacionais, além de haver uma grande instabilidade na renda obtida pelos pescadores. Com isto, as medidas de proteção social, proteção à saúde e garantia dos direitos desse segmento de trabalhadores, bem como a seus dependentes, têm importância primordial (LOURENÇO; HENKEL; MANESCHY, 2006; GOIABEIRA, 2012).

$O$ trabalho do pescador depende diretamente do meio ambiente, tornando-se necessário que haja pesquisas, políticas públicas efetivas para este público e orientações protetivas, o que exige deste profissional uma elaborada noção de preservação e proteção dos recursos naturais, não só com vistas à lucratividade advinda de seu trabalho, mas também com foco na sustentabilidade, garantindo que estes recursos também possam ser utilizados por gerações futuras. A degradação deste meio ambiente, onde se desenvolvem suas atividades de trabalho, refletirá diretamente em sua saúde, assim como as dos demais envolvidos na atividade da pesca.

Dito isto, é de fundamental importância melhorar a percepção ambiental desses atores, bem como, otimizar o uso dos recursos pesqueiros, como forma de ampliação da visão de responsabilidade com a manutenção dos recursos da natureza. Assim, a noção de preservação e do consumo consciente por este público, torna-se um desafio científico e político, pois depende de uma educação ambiental que incorpore valores e atitudes voltados à conservação do ambiente, remodelando todo um conjunto de atitudes, que são formadas e passadas de geração em geração, desenvolvendo a consciência ecológica deste público (SILVA, 2015).

A deficiência do poder público na fiscalização e monitoramento da "fronteira pesqueira", por exemplo, é um dos motivos que desestimulam a prática da pesca, por tornar esta atividade menos lucrativa ao reforçar a competição desordenada pela captura. Percebe-se que muitos filhos de pescadores estão 
buscando outras atividades econômicas e paulatinamente se afastando da pesca artesanal (CAPELLESSO; CAZELLA, 2011; SANTOS; SAMPAIO, 2013).

Para isso, é necessário também o reconhecimento de que os pescadores homens, mulheres e crianças "São categorias simultaneamente vulneráveis no âmbito social, diante da existência em condições de pobreza e resistentes ao manterem modos de trabalho tradicionais perante a gigantesca hegemonia da sociedade industrial e terciária" (PENA; MARTINS; REGO, 2013, p. 66).

A intervenção estatal por vezes reflete um desestímulo a atividade da pesca, a exemplo do projeto de urbanização da orla de Jaraguá que expulsou os pescadores moradores da comunidade da vila do Jaraguá para condomínios residenciais (ALBUQUERQUE; PEIXOTO; ALBUQUERQUE, 2012); questões de caráter social, como vulnerabilidade, e até econômicas, como a livre concorrência no mercado e uso de tecnologia, tem favorecido a precarização das condições de meio ambiente de trabalho da atividade da pesca artesanal. Uma vez que a pesca artesanal é uma modalidade econômica milenar que não se coaduna com a lógica capitalista (RAMALHO, 2015)

\section{Considerações finais}

Diante de todo exposto percebe-se que o tema da pesca artesanal vem sendo estudado pelos pesquisadores, porém, apresenta uma visão disciplinar, bem específica a alguns campos do conhecimento, carecendo assim de uma abordagem interdisciplinar.

Grande parte das pesquisas encontradas quando relacionadas ao "multiculturalismo" ou "pluralismo jurídico", usados como descritores desse mapeamento, tinham como objeto comunidades indígenas ou quilombolas não restando espaço para as comunidades tradicionais de pescadores artesanais.

E quando se procurava diretamente sobre a comunidade do Jaraguá o que se encontrava eram trabalhos focados na regularização fundiária e o direito de moradia dos pescadores.

O pescador do Jaraguá, mesmo diante de sua relevância histórica, cultural e econômica para o estado de Alagoas vem sendo agredido pela negligência do Poder Público e até mesmo ações equivocadas como a transferência compulsória da vila para conjuntos residenciais distantes.

As pesquisas mapeadas ainda mostram a crescente degradação ambiental da região seja através da poluição do meio ambiente natural da pesca seja do desequilíbrio gerado no meio ambiente de trabalho com os reflexos na saúde ocupacional e segurança dos pescadores. 


\section{Referências}

ALBUQUERQUE, A.A.; PEIXOTO, G.V.; ALBUQUERQUE, A.M.G. Uma demonstração do vigor da cidade: a resistência dos pescadores do Jaraguá, Maceió-AL. Anais do III Seminário Internacional Urbicentro. Bahia. Out. 2012. Disponível em <http://www.ppgau.ufba.br/urbicentros/2012/ST175.pdf> Acesso em 31 mai. 2017.

ALBUQUERQUE, U. P.; LINS NETO, E. M. F. Seleção dos participantes da pesquisa. In: ALBUQUERQUE, U. P.; LUCENA, R. F. P.; CUNHA, L. V. F. C. (Ed.). Métodos e técnicas na pesquisa etnobiológica e etnoecológica. Recife: Nupeea, 2010 (Coleção estudos e avanços).

ALVIM, R.G. As condições de vida dos pescadores artesanais de Rua da Palha. Acta Scientiarum. Human and Social Sciences, v. 34, p. 101-110, 2012.

BARROSO, L.R. Direito Constitucional e a Efetividade de suas Normas. 5은 Ed. Rio de Janeiro, Editora Renovar, 2001, p. 85.

BATES, D. G. Human adaptive strategies: ecology, culture, and politics. 3rd ed. Boston: Pearson Education, 2005.

BATES, D. G.; LEES, S. H. Case studies in human ecology. New York: Plenum Press, 1996.

BRASIL. Constituição da República Federativa do Brasil de 1988. Disponível em: $\quad$ <http://www.planalto.gov.br/ccivil 03/Constituicao/Constituicao.htm> Acesso em 10 out. 2016.

BRASIL. Lei no 11.959, de 29 de junho de 2009. Dispõe sobre a Política Nacional de Desenvolvimento Sustentável da Aquicultura e da Pesca, regula as atividades pesqueiras, revoga a Lei $\mathrm{n}-7.679$, de 23 de novembro de 1988, e dispositivos do Decreto-Lei no 221, de 28 de fevereiro de 1967, e dá outras providências. Disponível em: <http://www.planalto.gov.br/ccivil 03/ ato20072010/2009/lei//11959.htm> Acesso em 10 abr. 2017.

BRASIL. Decreto no $\mathbf{6 . 0 4 0}$ de 7 de fevereiro de 2007. Institui a Política Nacional de Desenvolvimento Sustentável dos Povos e Comunidades Tradicionais. <http://www.planalto.gov.br/ccivil 03/ ato2007-2010/2007/decreto/d6040.htm>, Acesso em 10 jun. 2017.

CARVALHO, I.G.S. et al. Por um diálogo de saberes entre pescadores artesanais, marisqueiras e o direito ambiental do trabalho. Ciênc. Saúde Coletiva, n. 10, p. 4011-4022, Out. 2014. Rio de Janeiro, v. 19.

CAPELLESSO, A.J.; CAZELLA, A.A. Pesca artesanal entre crise econômica e problemas socioambientais: estudo de caso nos municípios de Garopaba e Imbituba (SC). Ambient. Soc., São Paulo, v. 14, n. 2, p. 15-33,

CRESWELL, J.W. Projeto de Pesquisa: métodos qualitativos, quantitativos e mistos. 3ํe. ed. Porto Alegre, Artmed: 2010. 
DIEGUES, A.C. Pescadores, camponeses e trabalhadores do mar. São Paulo: Ática, 1983.

FAO - Organização das Nações Unidas para Agricultura e Alimentação (2014). O estado da pesca e da aquacultura no mundo. Roma, 2012. Disponível em <http://www.fao.org/3/a-i3720e.pdf> Acesso em 13 Mai. 2017.

FREITAS, M.B.; RODRIGUES, S.C.A. As consequências do processo de desterritorialização da pesca artesanal na Baía de Sepetiba (RJ, Brasil): um olhar sobre as questões de saúde do trabalhador e o ambiente. Ciênc. Saúde Coletiva, Rio de Janeiro, v. 19, n. 10, p. 4001-4009, Out. 2014..

FREITAS, M.B.; RODRIGUES, S.C.A. Determinantes sociais da saúde no processo de trabalho da pesca artesanal na Baía de Sepetiba, estado do Rio de Janeiro. Saúde Soc., São Paulo, v. 24, n. 3, p. 753-764, Set. 2015. Disponível em <http://www.scielo.br/scielo.php?script=sci_arttext\&pid

GARRONE NETO, D.; CORDEIRO, R.C.; HADDAD JR., V. Acidentes do trabalho em pescadores artesanais da região do Médio Rio Araguaia, Tocantins, Brasil. Cad. Saúde Pública, Rio de Janeiro, v. 21, n. 3, p. 795-803, Jun. 2005.

MAPA, 2013. Ministério da Agricultura, Pecuária e Abastecimento. Disponível em <http://www.agricultura.gov.br/assuntos/pesca-e-aquicultura> Acesso em 15 de abr. de 2017

MARTINS, M.L.S.; ALVIM, R.G. Perspectivas do trabalho feminino na pesca artesanal: particularidades da comunidade llha do Beto, Sergipe, Brasil. Bol. Mus. Para. Emílio Goeldi. Ciênc. Hum., Belém, v. 11, n. 2, p. 379-390, Ago. 2016.

MESQUITA, E.M.C.; ISAAC-NAHUM, V.J. Traditional knowledge and artisanal fishing technology on the Xingu River in Pará, Brazil. Braz. J. Biol., São Carlos, v. 75, n. 3, supl. 1, p. 138-157, Ago. 2015.

MOTA, D.M.; SCHMITZ, H.; SILVA JUNIOR, A. (Dis)agreements on the use of natural resources within a context of land transformation in Sergipe. Ambient. Soc., São Paulo, v. 18, n. 2, p. 41-58, Jun. 2015.

MOTA, D.M. et al. O trabalho familiar extrativista sob a influência de políticas públicas. Rev. Econ. Sociol. Rural, Brasília, v. 52, supl. 1, p. 189-204, 2014.

OLIVEIRA, B.M.C. Percepção ambiental dos pescadores de marisco do litoral norte de Pernambuco. Anais do III Congresso Brasileiro de Gestão Ambiental. Goiânia/GO. Nov. 2012 . Disponível em $<$ http://www.ibeas.org.br/congresso/Trabalhos2012/XI-043.pdf> Acesso em 31 mai. 2017.

ORGANIZAÇÃO INTERNACIONAL DO TRABALHO - OIT. Convenção 188. Disponível em <http://www.oitbrasil.org.br/content/referente-ao-trabalho-napesca> Acesso em 10 abr. 2017

PENA, P.G.L.; MARTINS, V.; REGO, R.F. Por uma política para a saúde do trabalhador não assalariado: o caso dos pescadores artesanais e das

revista brasileira educação ambiental 
marisqueiras. Rev. Bras. Saúde Ocup., São Paulo, v. 38, n. 127, p. 57-68, Jun. 2013.

PENA, P.G.L.; FREITAS, M.C.S.; CARDIM, A. Trabalho artesanal, cadências infernais e lesões por esforços repetitivos: estudo de caso em uma comunidade de mariscadeiras na llha de Maré, Bahia. Ciênc. Saúde Coletiva, Rio de Janeiro, v. 16, n. 8, p. 3383-3392, Ago. 2011.

PINTO, S.R.; AVILA, C.F.D. Sociedades plurales, multiculturalismo y derechos indígenas en América Latina. Polít. Cult., México, n. 35, p. 49-66, Jan. 2011.

PRADO JÚNIOR, C. História econômica do Brasil. 43 ed. São Paulo. Brasiliense, 2012.

RAMALHO, C.W.N. A desnecessidade do trabalho entre pescadores artesanais. Sociologias, Porto Alegre, v. 17, n. 38, p. 192-220, Abr. 2015.

RAMALHO, C.W.N. Pescados, pescarias e pescadores: notas etnográficas sobre processos ecossociais. Bol. Mus. Para. Emílio Goeldi. Ciênc. hum., Belém, v. 11, n. 2, p. 391-414, Ago. 2016.

ROA, J.E.R. Pluralismo jurídico y mecanismos de coordinación entre los sistemas de justicia indígena y el sistema nacional de justicia en Colombia. Rev. Derecho Estado, Bogotá, n. 33, p. 101-121, Jul. 2014.

SANTOS, E.C.; SAMPAIO, C.L.S. A Pesca Artesanal na Comunidade de Fernão Velho, Maceió (Alagoas, Brasil): de Tradicional a Marginal. RGCI, Lisboa, v. 13, n. 4, p. 413-424, dez. 2013.

SILVA, J.A. Direito Constitucional Ambiental. São Paulo: Malheiros, 2004.

TREVIZAN, S.D.P.; LEAO, B.M. Pluralidade jurídica: sua importância para a sustentabilidade ambiental em comunidades tradicionais. Soc. Estado., Brasília, v. 29, n. 2, p. 539-560, Ago. 2014.

TÓMAZ, A.F.; MARQUES, J. (org.). Ecologias Humanas. Feira de Santana-BA. UEFES, 2014. 462 p. il.

VARGAS, S.F.; LASCARRO, A.A. Derecho a la autodeterminación de los pueblos indígenas en el ordenamiento jurídico colombiano. Rev. Estud. Soc., Bogotá, n. 53, p. 65-76, Jul. 2015.

WOLKMER, A.C. Pluralismo Jurídico: Fundamentos de uma nova cultura no Direito. 3ำ ed. São Paulo: Alfa Ômega, 2001. 